\title{
O CURSO DE PEDAGOGIA NA UFERSA EM ANGICOS/RN: UM INÉDITO-VIÁVEL FREIREANO
}

DOI: $10.48075 /$ RI.V24I2.26622

Francisco Canindé da Silva ${ }^{1}$ Divoene Pereira $\mathrm{Cruz}^{2}$

RESUMO: No ano em que marca o centenário de seu nascimento (2021), Paulo Reglus Neves Freire continua sendo entre educadores brasileiros e do mundo, uma das maiores forças do pensamento crítico-progressista, sem a ele reduzir-se. Sua pedagogia tem fundamentado inúmeros projetos, programas, trabalhos acadêmicos científicos, curso de formação de professores, licenciaturas e outras tantas práticas educativas. Essa afirmação é realçada nesse trabalho, cujo objetivo é evidenciar o Curso de Pedagogia da UFERSA - no município de Angicos/RN, enquanto um espaçotempo de formação freireana, como constatamos em seu Projeto Pedagógico de Curso (PPC) e no relato de uma professora do referido curso. Na cidade em que este pensador colocou em prática o projeto das 40 horas de alfabetização de jovens e adultos, cinquenta anos depois, seu pensamento novamente se encarnará, desta feita em uma proposta de formação inicial de pedagogos/professores, reinventando-se como inédito-viável.

\section{THE COURSE OF PEDAGOGY AT UFERSA IN ANGICOS/RN: A FREIREAN UNTESTED FEASIBILITY}

ABSTRACT: In the year that marks the centenary of his birth (2021), Paulo Reglus Neves Freire continues to be, among Brazilian and world educators, one of the greatest forces of criticalprogressive thinking, without reducing himself to it. His pedagogy has been the foundation of numerous projects, programs, academic scientific works, teacher training courses, undergraduate courses and many other educational practices. This declaration is emphasized in this work, whose

\footnotetext{
1 Professor do Departamento de Educação/Curso de Pedagogia do Campus Avançado da Universidade do Estado do Rio Grande do Norte (UERN) e do Programa de Pós-Graduação em Educação (POSEDUC) da Faculdade de Educação da UERN. Doutor em Educação pelo Programa de Pós-Graduação em Educação (ProPEd) da Universidade do Estado do Rio de Janeiro (UERJ). Líder do Grupo de Estudos e Pesquisas em Educação de Jovens e Adultos (GEPEJA). E-mail: caninprof@hotmail.com

2 Professora do Curso de Pedagogia da Universidade Federal Rural do Semiárido (UFERSA), Campus de Angicos/RN. Doutora em Educação pelo Programa de Pós-Graduação em Educação (PPGED) da Universidade Federal do Rio Grande do Norte (UFRN). Líder do Grupo de Pesquisa Educação, Educação de Jovens e Adultos, Educação do Campo, Currículo e Prática Pedagógica (PRAEJA). E-mail: Divoene.pereira@ufersa.edu.br
} 
objective is to highlight the Pedagogy Course at UFERSA - in the city of Angicos/RN, as a space-time of Freire's training, as we can see in the Course's Pedagogical Project (PPC) and in the report of a teacher from the said course. In the city in which this thinker put into practice the 40-hour literacy program for young people and adults, fifty years later, his thinking will once again be incarnated, this time in a proposal for initial training of pedagogues/teachers, reinventing itself as untested feasibility.

Key Words: Freirean thought; Pedagogy Course; Teacher training.

\section{INTRODUÇÃO}

A trama social e o drama político em que o pensamento de Paulo Freire vem sendo submetido, após o Golpe de Estado de 2016, quando a presidenta eleita em seu segundo mandato (2015 a 2016), pelo voto popular - Dilma Rousseff - foi retirada injustamente da Presidência da República Federativa do Brasil, são terrivelmente prejudiciais as lutas das classes populares, especificamente dos professores e das políticas públicas para educação que the são inerentes, historicamente. Os ataques à obra, pensamento e história de Paulo Freire, são um epistemicídio a tudo que este encarnado educador representa para a educação brasileira.

A opção preferencial pelos oprimidos, desde a livre escolha de não seguir a carreira de advogado em Recife nos idos da década de 1950, quando em sua primeira causa optou pelo acusado em detrimento de suas condições de pobreza, Paulo Freire não só abandou o processo jurídico, como mergulhou naquilo tempos depois denominou de Educação como prática de liberdade; Pedagogia do oprimido, Pedagogia da esperança; A importância do ato de ler; Ação Cultural para a liberdade; Pedagogia da indignação e outros, para reivindicar com os grupos e movimentos populares por uma sociedade mais justa, em que o direito à vida na sua ampla rede de possibilidades fosse plenamente realizável. Utopia inicial que tem mobilizado o sonho de muitos jovens, adultos e idosos professores progressistas deste país e, quiçá, do mundo que creem e lutam para que o direito à vida seja garantido, dirimindo situações de miséria em que grupos populares foram e são colocados, assim como a sua profissão de professor.

O desafio que se coloca nesse sentido é de desinvisibilizar iniciativas existentespossíveis e potencializá-las no sentido de estender sempre e cada vez mais redes de 
conhecimentos freireanos, não para homogeneizar práticas e projetos, mas para também articular outros pensamentos democratizantes em curso. Como o próprio Freire afirmou com a publicação de Pedagogia da Esperança em 1992, é possível "soldar" conhecimentos desligados, percebendo seu parentesco.

A "soldadura" e a "ligadura" proposta neste reencontro com a Pedagogia do oprimido, em Pedagogia da esperança nos conduz ao reconhecimento de que o trabalho a partir de seu pensamento é um trabalho semiaberto, passível de conexões com outras propostas de orientação democratizante, e de que aquelas propostas em efetivo exercício, em muitas escolas e iniciativas não escolares não são a sua reprodução, mas ampliação, pois a obra se dilata e se fortalece continuamente, com processos de releitura.

O Curso de Pedagogia da Universidade Federal Rural do Semiárido (UFERSA) Campus de Angicos/RN é um desses exemplos vivificados da pedagogia de Paulo Freire. Na terra em que desenvolveu sua experiência inicial com o método de alfabetização com jovens e adultos - por um lado, jovens estudantes universitários, animadores dos círculos de cultura; de outro, jovens, adultos e idosos sem as capacidades de leitura e escrita básicas, animados por essa iniciativa. Uma síntese história: jovens e adultos aprendendo simultaneamente em 40 horas com suas experiências de vida e de formação.

O Curso de Pedagogia na UFERSA/Angicos, criado com fundamentos na filosofia/pedagogia freireana, implica uma continuidade e a reencarnação de uma epistemologia e de uma política que continua sendo muito necessária a população econômica, social e culturalmente marginalizada pelo modelo de sociedade (de ciência e política hegemônicos) que a sustentam.

Portanto, evidenciar o Curso de Pedagogia da UFERSA - no município de Angicos/RN, enquanto um espaçotempo de formação freireana, se constitui principal objetivo desse trabalho, cuja metodologia se organiza interdependentemente em torno de dois pontos, a saber: a análise do Projeto Pedagógico de Curso (PPC), que apresenta processos históricos constitutivos; fundamentos teórico-metodológicos; organização curricular e resultados esperados, que serão discutidos neste primeiro momento. Em seguida trabalharemos com o relato de 01 professora efetiva do referido curso, para que possamos reconhecer outros 
indicativos de como essa proposta de formação em nível de licenciatura vem se materializando no Campus da UFERSA em Angicos/RN.

Desta maneira, começaremos o diálogo entrecruzando o dito no PPC na relação com alguns princípios assumidos pelo educador Paulo Freire. Em seguida, estabeleceremos um diálogo com o relato da professora, atribuindo reflexões e ressignificações possíveis, sem a tentativa de manipular dados, mas apenas de traduzir como inédito-viável esse processo de formação inicial de professores.

O inédito-viável em Paulo Freire assume a dimensão do ainda-não do Ernest Bloch (2015), daquilo que existe em potência decorrente das múltiplas relações criadas. Nas palavras de Freire (2018, p. 263), o inédito-viável não é apenas uma simples junção de letras, mas "Uma palavra epistemologicamente empregada por Freire para expressar, com enorme carga afetiva, cognitiva, política, ética e ontológica, os projetos e os atos das possibilidades humanas".

Assim, esperançamos que o texto possa se constituir, pela apresentação do curso, um inédito-viável, no contexto do amplo movimento que universidades, grupos de pesquisas, educadores, educadoras, educandos e educandas vem mobilizando em torno dos 100 anos de Paulo Freire que será comemorado em setembro de 2021.

\section{O PPC DO CURSO DE PEDAGOGIA DA UFERSA/ANGICOS E O PENSAMENTO FREIREANO; UMA REDE DE INÉDITOS-VIÁVEIS EM CONTEXTO DE TEXTO}

Historicamente situando, a criação do Curso de Pedagogia na UFERSA, Campus de Angicos teve seu início em novembro de 2013 quando se instituiu por meio da Portaria no 1.629/2013, a comissão para reformulação do PPC. A criação da comissão para revisão do projeto de Curso de Pedagogia já existente na UFERSA (mas, não no Campus de Angicos) agregou princípios, valores e fundamentos freireanos, inclusive com perspectivas que possibilitassem a formação do pedagogo para o trabalho com Educação de Jovens e Adultos, área descoberta pela maioria dos cursos de pedagogia espalhados nas universidades e faculdades brasileiras. 
De acordo com o Projeto Pedagógico, o Curso de Licenciatura em Pedagogia foi aprovado por Decisão CONSEPE/UFERSA № 036/2016, na 7ạ Reunião Ordinária de 2016, em sessão realizada no dia 17 de novembro do mesmo ano, e seu início aconteceu em junho de 2017.

A abertura do Curso se deu logo após a trágica derrota que a Constituição e a democracia brasileira sofreram com o impeachment da Presidenta Dilma Rousseff. Embora o acontecimento tenha fragilizado forças de esquerda e de movimentos populares como um todo, no Brasil, o sonho da continuidade de um projeto de democratização se manteve forte em alguns movimentos e instituições até os dias atuais.

De acordo com o PPC a reformulação do projeto aconteceu no contexto das comemorações dos 50 anos da experiência das 40 horas, fato que marcou não somente a alfabetização, mas a politização de 300 jovens e adultos no início da década de 1960 e o começo da trajetória de Freire enquanto educador progressista.

No processo de reformulação desse PPC foram incorporadas contribuições da minuta do projeto encaminhado ao Ministério da Educação e recomendações da Comissão Nacional "Angicos 50 Anos", bem como da Comissão Regional que organizou, em 2013, as comemorações alusivas ao Cinquentenário das 40 Horas de Angicos (UFERSA, 2016, p. 8).

A comissão que presidiu a reformulação do projeto de curso, contextualizando-o a realidade local do semiárido nordestino e de Angicos especificamente, indicaram no corpo do texto a possibilidade de o pedagogo em formação desenvolver "competências e habilidades para atuar em espaços escolares e não escolares no âmbito das especificidades da Educação de Jovens e Adultos" (UFERSA, 2016, p. 8). Decisão que refletirá na organização da matriz curricular, ao adotarem os seguintes componentes curriculares obrigatórios: "Desenvolvimento Cognitivo e Aquisição da Leitura e da Escrita em EJA"; "Inclusão Digital e EJA"; "Estágio Supervisionado III: Educação de Jovens e Adultos"; e "Educação de Jovens e Adultos (EJA)".

Além destes componentes específicos da EJA, componentes relacionais, como: "Educação em direitos humanos"; "Educação Popular e Pedagogia social no Brasil"; "Educação do campo"; "Movimentos sociais e cidadania"; “Ação Educativa em Espaços NãoEscolares"; "Políticas e Organização da Educação no Sistema Prisional"; "Educação, Meio 
Ambiente e Sustentabilidade" também estão no leque dos componentes obrigatórios do citado projeto de curso.

O conjunto dos componentes curriculares, acima citados, são referenciados por componentes curriculares da área de fundamentos, tais como: "Fundamentos TeóricoMetodológicos da Concepção Freireana de Educação"; "Fundamentos Históricos e Materiais da Produção da Existência dos Homens e Mulheres do Semiárido Brasileiro; e "Legislação, Políticas e Diretrizes para a EJA", demonstrando a implicada rede de saberesfazeres (PAIVA; OLIVEIRA 2001) que se constitui nesse contexto, um inédito-viável à formação de pedagogos/professores.

O caráter democratizante que assume o projeto pedagógico de curso, ao inserir componentes de EJA e áreas afins, revela a força que a Pedagogia do Oprimido tem nesse processo de elaboração do projeto. Podemos afirmar que em uma releitura de Pedagogia do oprimido, na atualidade, a opção por grupos populares oprimidos: não alfabetizados, negros, indígenas, quilombolas, ribeirinhos, LGBTQIA+ etc. seria novamente priorizados.

Os homens e mulheres que têm seus direitos historicamente negados, somente serão reconhecidos quando perceberem como o opressor faz hospedagem em suas vidas. Sobre esse aspecto, Boff (2006, p. 7) no prefácio a Pedagogia da Esperança, afirma: "é uma pedagogia que permite ao oprimido extrojetar de dentro de si e, por ele mesmo, o opressor a fim de resgatar seu ser-livre". Assim, compreendemos que é pela formação implicada com essas populações marginalizadas, reconhecendo suas potencialidades que a liberdade se fará prática contínua.

Entrecruza essas opções teóricas, políticas e epistemológicas, uma Pedagogia da esperança que se experimenta pela inserção crítica de conteúdos e experiências tecidas culturalmente por grupos populares, severamente silenciados e por muito tempo sucumbido de seus direitos de sonhar, exilado em sua própria dimensão de existência no mundo social. A tarefa, portanto, de um curso de pedagogia consiste em "possibilitar nas classes populares o desenvolvimento de sua linguagem" (FREIRE, 1992, p. 41), articulando a leitura ordinária (CERTEAU, 2011) dos grupos populares como invenção de um processo democratizante, e não apenas subordinando-o a uma gramaticalização de conteúdo.

A forma crítica de compreender e de realizar a leitura da palavra e a leitura do mundo está, de um lado, na não negação da linguagem simples, Ideação. Revista do Centro de Educação, Letras e Saúde. v. 23, n², 2021. e-ISSN: 1982-3010. 


\begin{abstract}
"desarmada", ingênua, na sua não desvalorização por constituir-se de conceitos criados na cotidianeidade, no mundo da experiência sensorial; de outro, na recusa ao que chama de "linguagem difícil", impossível, porque desenvolvendo-se em torno de conceitos abstratos (FREIRE, 1994, p. 33$34)$.
\end{abstract}

Considerar linguagens dos sujeitos praticantes dos cotidianos em um Curso de Pedagogia, requer de seus propositores e de seus educadores uma coerência ética e política com o quefazer formativo, especificamente quando se vivencia no contexto da educação brasileira uma BNC formação que, no mínimo, desrespeita as trajetórias profissionais dos professores das universidades públicas.

Neste sentido, percebemos que o componente curricular "Fundamentos Históricos e Materiais da Produção da Existência dos Homens e Mulheres do Semiárido Brasileiro" traduz-se como indicativo de uma prática inclusiva das linguagens com as quais os sujeitos operam cotidianamente. Licenciandos com suas linguagens de mundo, transformando-as e potencializando-as no decorrer do curso; quando egressos, poderão reconhecer linguagens no processo formativo de crianças, jovens, adultos e idosos de projetos de alfabetização, na Educação Básica ou em outros espaços em que desenvolverão suas atividades profissionais.

Nos princípios epistemológicos e educativos assumidos no projeto de curso de Pedagogia da UFERSA em Angicos/RN, evidenciamos a relação implicada dos componentes com essas linguagens dos grupos populares, entrelaçando-se como aposta ao processo formativo, encarnado em uma Pedagogia do Oprimido e da Esperança, que se faz com os sujeitos e seus saberes de mundo, identificando-os e reconhecendo-os, simultaneamente, como existente-possível, ou seja, como alternativa ao autoritarismo dos conteúdos cientificistas do paradigma dominante.

Nesse sentido, Freire (2001, p. 78) nos alerta para que a consciência crítica e a ética do educador (do formador) articule enquanto dispositivo de ensino-aprendizagem, linguagens e experiências culturais cotidianas, a fim de construir com os educandos sua autonomia, assumindo como tarefa fundante a libertação da condição de ingenuidade dos educandos. "Não é para encorajar os objetivos do educador e as aspirações e os sonhos a serem reproduzidos nos educandos, os alunos, mas para originar a possibilidade de que os estudantes se tornem donos de sua história". 
O princípio freireano da dialogicidade, tomado como princípio no PPC do referido curso, reforça a relevância de se manter um diálogo permanente com os saberes dos sujeitos, entendendo-os enquanto demanda formativa crítica. Se a proposta é verticalizada, por mais que se identifique rastros de processos formativos democráticos, ao final da formação ter-se-á priorizado a lógica hegemônica de conhecimento que mais serve aos propósitos de grupos opressores do que propriamente as necessidades vitais dos grupos populares.

[...]o diálogo freireano deve começar já na "busca do conteúdo programático", em que estão implicados saberes diferentes, que não podem ser impostos por alguém, mas podem emergir a partir da comunicação crítica e esperançosa sobre nossa condição no mundo (ZITKOSKY, 2018, p. 138).

A prática do diálogo é, portanto, necessária a formação crítica do sujeito - do educador (do pedagogo) formador e dos educandos (pedagogos) em processo de formação inicial. "A prática da relação dialógica é, neste sentido, fundamental para romper, por um lado, com o silêncio e, por outro, para promover a reflexão sobre as contradições, a partir, principalmente, da problematização da realidade" (UFERSA, 2016, p. 44).

O desafio do diálogo, que é impossível acontecer sem a relação horizontalizada entre os sujeitos é ampliada no documento em questão, quando os organizadores estabelecem outros princípios epistemológicos e educativos a saber: a conscientização; a transformação da realidade; a realidade concreta; o conhecimento enquanto processo; o respeito ao outro como legítimo em processos de cooperação; o comprometimento; o aperfeiçoamento contínuo; o enfoque social; a contextualização; a relação teoria-prática e a inovação, todos fundamentados na pedagogia freireana, direta ou indiretamente. Entendemos que ao adotarem esses princípios, estabelecem conexões profundas com princípios freireanos, tais como: o princípio da liberdade, da leitura de mundo, da politicidade, da problematização, da conectividade etc.

Diríamos, então, que a formação inicial de pedagogos/professores na relação com a pedagogia freireana são atravessados, do ponto de vista do PPC, por processos crescentes e desafiadores para aqueles que educam, na condição de professores-formadores, visto que 
precisam, para além da normatização colocada pelas diretrizes curriculares nacionais, expedidas pelo Ministério da Educação, estarem atentos as demandas e contextos locais.

É desse movimento que Linhares (2004) se reporta, ao pensar a formação de professores em contextos da comunidade científica e poética - da multiplicidade e vastidão das urgências identificadas nos grupos populares.

[...]os movimentos necessários para forjarmos outras formas de conviver, produzir, pensar e compartilhar a vida, mais solidariamente, não se encontram num além, sobreposto ao nosso cotidiano de mulheres e homens, esperando apenas que os sagazes e geniais os "descubram" para usá-los e aplicá-los, mas está entre nós, como relações integrantes de nossas vidas, que cobram sempre outras elaborações, capazes de ressignificar práticas sociais de forma criadoramente ética (LINHARES, 2004, p. 16).

O desafio, portanto, será o da coerência política, cultural e epistemológica com o grupo de jovens, adultos e idosos que buscam o Curso de Pedagogia, na referida universidade. A região do semiárido nordestino e seus habitantes, produzem saberes possíveis de diálogo educativo no contexto de um curso de licenciatura, especificamente de um curso de pedagogia freireano, cuja aposta é a formação enraizada identitária, de valorização local.

\section{A FORMAÇÃO DOCENTE NO CONTEXTO DO CURSO DE PEDAGOGIA DA UFERSA EM} ANGICOS/RN: IMPLICAÇÕES OUTRAS

No contexto das Diretrizes Nacionais para os cursos de licenciaturas, recomendadas pelo Ministério da Educação (MEC), são diversas as condições, exigências e requisitos para que os sujeitos ingressos possam alcançar a profissionalização esperada e construam continuadamente capacidades para o desenvolvimento de suas atividades. Embora a Resolução CNE/CP № 2 de 20 de dezembro de 2019 seja um insulto a autonomia dos cursos de licenciatura, com a BNC formação, acreditamos que os fundamentos axiológicos, epistemológicos e políticos dos cursos se manterão fortes o suficiente para essa batalha. 
O curso de Pedagogia da UFERSA em Angicos/RN, denominado política e epistemologicamente freireano, certamente travará uma luta diária para manter viva essa chama que desde 1962 foi acesa, por meio das 40 horas de alfabetização. Não há mais como retroceder, vincular e restringir ao curso, a aplicação de um conjunto de diretrizes curriculares que prioriza o aprendizado de competências e habilidades "ocas" afirmando ser necessária essa qualificação para o desenvolvimento econômico e social do país.

A formação docente que o referido curso propõe, nessa universidade, prescinde de implicações reais da cultura e da vivência cotidiana dos sujeitos que convivem no Semiárido do estado do Rio Grande do Norte, como ressalta a professora do Curso de Pedagogia nossa colaboradora nesse estudo - ao afirmar que quando chegou na UFERSA, Campus de Angicos, procurava Paulo Freire nos cotidianos dos professores, técnicos e alunos, mas não encontrava-o facilmente.

Quando cheguei em Angicos, em 2017, apaixonada por Freire e tudo que sua concepção de educação representa para nossa luta de trabalhadores assentados, senti sua falta...e me perguntava: como uma universidade pública, situada em Angicos/RN não tinha essa adesão a Paulo Freire?" (PROFESSORA GIRASSOL, 2020).

O relato da Professora Girassol, evidencia a necessidade de identificar no cotidiano da UFERSA práticas político-pedagógicas vivenciadas com a filosofia freireana, inicialmente experienciada naquele lugar - Angicos em quarenta horas. Concursada para o cargo efetivo de professora e ainda sem a implantação do Curso de Pedagogia, a referida professora começa a mobilizar aqueles espaços com sua principal referência teórico-metodológica, a pedagogia freireana. Neste mesmo ano, criou um grupo de pesquisa denominado de Práticas Educativas em Educação de Jovens e Adultos (PRAEJA), com o qual desenvolveu o primeiro projeto de pesquisa em 02 escolas da rede municipal de Angicos, 01 na zona rural e outra na zona urbana, sendo que na escola da zona urbana, encontrou maior receptividade, segundo nos relatou a Profa. Girassol.

Nossa intenção foi de aproximar a realidade das escolas que trabalhavam com a EJA, da rede municipal com a universidade e os cursos lá existentes. Embora lá, na UFERSA, já existisse o Memorial Paulo Freire, a relação com a comunidade era mínima, e com o imaginário freireano das 40 horas, era também muito incipiente (PROFESSORA GIRASSOL, 2020). 
Com duas bolsistas, a Profa. Girassol enfrenta o desafio de desenvolver o projeto nestas escolas, analisa seus Projetos Políticos Pedagógicos e discute reflexivamente com os professores das referidas escolas, práticas pedagógicas desenvolvidas na EJA, buscando reconhecer indícios de um saber-fazer implicado com a região do Semiárido - fazer a leitura de mundo. A esse respeito, Passos (2018, p, 286) comenta: “Há um papel pedagógico e político nesse processo: troca de saberes, interlocução, compartilhamento solidário". É dessa maneira que a Professora Girassol vai se implicando para traduzir a realidade das escolas que trabalham com EJA, remexendo, revivendo com os professores e com os bolsistas a pedagogia freireana.

Com a implantação do Curso de Pedagogia no ano de 2017, resultado das forças políticas e pedagógicas empreendidas pelos professores, coordenadores e reitoria da UFERSA desde o ano de 2013, a perspectiva pedagógica freireana se dilatou e impulsionou outras iniciativas e parcerias com a comunidade local e municípios vizinhos. Dentre essas atividades, as instalações da Universidade e seu corpo docente passaram a desenvolver projetos com professores da Educação Básica e também a sediar eventos, tais como: jornadas pedagógicas da rede municipal e da rede estadual, cursos de formação continuada de professores, semana de cultura, etc.

\begin{abstract}
Após a implantação do Curso de Pedagogia, passei a trabalhar com as disciplinas específicas da EJA e daquelas com abordagens mais freireanas. Foi nesse momento que me encontrei, realmente, dentro da UFERSA e comecei a pensar e desenvolver projetos com essa fundamentação teórica libertadora. Como vim de Assentamento dos Sem-Terra, fui professora em uma escola do Assentamento, e ainda hoje resido naquele espaço, entendo que a formação dos professores tem que ter implicação com a realidade social de seus estudantes. Eles precisam aprender a trabalhar a terra onde vivem. É pelo ato político-pedagógico enraizado no cotidiano que isso é possível (PROFESSORA GIRASSOL, 2020).
\end{abstract}

Percebemos que as ações que começaram a se desenvolver após a criação e implantação do Curso de Pedagogia reacenderam as esperanças de educadores das rede municipal e estadual do município de Angicos e circunvizinhos. A Pedagogia do oprimido ressurge com toda sua força, produzindo aquilo que ela mais incita em educadores progressistas - esperançar - lutando e resistindo ao projeto de ódio sempre vivo e atualmente em ascensão com este (des)governo de Jair Bolsonaro. 
Um exemplo caro a nossa professora colaboradora, é o Projeto de Extensão por ela desenvolvida sobre a Educação de Jovens e Adultos na perspectiva freireana, que atende no formato remoto (em função do momento pandêmico provocado pela COVID-19) cem professores da Educação Básica que trabalham com a EJA ou têm interesse na discussão.

Esse momento político que estamos vivendo, nos lembra, para não esquecermos (RICOEUR, 2007), outro momento histórico brasileiro, o da Ditadura Militar, ao qual Thiago de Mello (1996, p, 30) nos faz rememorar em forma de poesia:

Peço licença para avisar que, ao gosto de Jesus, Este homem renascido é um homem novo: Ele atravessa os campos espalhando A boa-nova, e chama os companheiros A pelejar no limpo, fronte a fronte, Contra o bicho de quatrocentos anos, Mas cujo fel espesso não resiste A quarenta horas de total ternura.

Desse modo, acreditamos que o Curso de Pedagogia na UFERSA em Angicos/RN tem lutado, nesse contexto, contra esse 'bicho' antidemocrático que vem minando direitos dos grupos populares - o capitalismo. Ao inserir a cultura e vivências cotidianas locais, o referido curso marca a opção pela luta, transformação social e prática de liberdade tão cara aos nossos estudantes e professores, nesse caso, mais especificamente da Professora Girassol, moradora e militante do MST.

Assim, acreditamos que essas implicações outras, que fogem ao roteiro da prescrição, do desenvolvimento de competências e habilidades são inéditos-viáveis, justo porque "o inédito-viável é uma proposta prática de superação, pelo menos em parte, dos aspectos opressores percebidos na realidade" (FREITAS, 2001, p. 29). Segundo a autora, o risco de assumir a luta pelo inédito-viável é próprio da natureza esperançosa dos educadores críticos, pois a reflexão e ação dos inéditos-viáveis derrubam as situações-limites que se nos apresenta como colonialismo, imperialismo, dominância, opressão, escuridão, escravidão etc.

A questão do inédito-viável na formação de pedagogos e professores por meio do Curso de Pedagogia da UFERSA em Angicos/RN, representa a força e a luta pela autonomia 
docente, que é também a autonomia universitária - maneiras de educar em relação com a pluralidade que é a uni-pluri-di-versidade.

São esses movimentos de autonomia que não só confirmam um tipo de autoridade dos professores, fortalecendo possibilidades de respeito entre pares, mas tendem a ultrapassar esse círculo, envolvendo os próprios estudantes, os auxiliares, os familiares e o entorno [universitário] para atingir a própria sociedade (LINHARES, 2004, p. 60).

Devemos, já próximos de concluir, acrescentar que formar pedagogos, professores, a partir de inéditos-viáveis para superar situações-limite nos coloca o desafio de optar pelos os despossuídos da história - mulheres, meninos, meninas, idosas, idosos, homens, jovens que tem seu direito a vida raptado. Formar nesta perspectiva, portanto, ganha status de justiça social, de democratização e emancipação social, que ocorre processualmente, a cada dia, nas interações que estabelecemos por meio do diálogo.

\section{CONSIDERAÇÕES FINAIS}

Evidenciar o Curso de Pedagogia da UFERSA - no município de Angicos/RN, enquanto um espaçotempo de formação freireana, objetivo principal desse trabalho, nos possibilitou conhecer mais aproximadamente sua organização curricular e intenções políticopedagógicas, corroborando com a hipótese de que o referido curso, se constitui um inéditoviável freireano para educadores e educandos da região do Semiárido nordestino e da Região Central do Rio Grande do Norte, especialmente Angicos, lugar em que está instalada a referida universidade.

O Projeto de Curso deixa evidente a perspectiva filosófica freireana de reconhecer, valorizar e potencializar os saberes locais, produzidos pelos sujeitos dessa região, constatado na escolha de componentes curriculares, tais como Fundamentos Históricos e Materiais da Produção da Existência dos Homens e Mulheres do Semiárido Brasileiro. Essa escolha política apresenta-se em nossa discussão como inédito-viável, por traduzir-se em compromisso ético-político dos professores e construtores do projeto com a formação do público em questão, que ao fazê-la põe-se na luta para incluir como conhecimento válido, saberes produzidos na experiência cotidiana dos sujeitos. 
Assumir essa posição política tem relação direta com os fundamentos teóricos, metodológicos e axiológicos freireanos, para os quais o conhecimento de mundo, ou a leitura de mundo precede a leitura da palavra, transformando o ser humano na justa ligação daquilo que sabe, incompletamente, com aquilo que pela reflexão dialógica passará a conhecer.

A formação em pedagogia, passa a se constituir no contexto da UFERSA em Angicos/RN, um ato político crítico-progressista, um ato de reencarnação freireana - pelo maneira como os professores formadores assumem e difundem por meio de suas ações docentes o trabalho de libertação.

Com pouco tempo de funcionamento, o referido curso tem produzido, além das ações pedagógicas cotidianas, outras de caráter mais amplo: Seminários de integração com a comunidade; realização de rodas de conversas com alguns dos ex-coordenadores e exalunos dos círculos de cultura das 40 horas; fomentado o Memorial Paulo na universidade; estabelecido diálogo com outros cursos de Pedagogia das universidades estadual e federal do Estado do Rio Grande do Norte, e até com professores de universidades e cursos de outros estados brasileiros.

O curso tem se projetado e desenvolvido um trabalho rigoroso com a proposta de formação de pedagogos e de professores com fundamentação freireana, não simplesmente fazendo os estudantes conhecerem a teoria freireana, mas principalmente ao realizar ações político-pedagógicas condizentes com essa teoria.

\section{REFERÊNCIAS}

BOFF, L. Prefácio a Pedagogia da Esperança. In: FREIRE, P. Pedagogia da esperança: um reencontro com a Pedagogia do oprimido. 13. ed. Rio de Janeiro: Paz e Terra, 1992.

BLOCH, E. O princípio esperança. Trad. Nélio Schneider. Rio de Janeiro: EdUERJ/Contraponto, 2005.

BRASIL. Ministério da Educação. Diretrizes Curriculares Nacionais para a Formação Inicial de Professores para a Educação Básica e Base Nacional Comum para a Formação Inicial de Professores da Educação Básica (BNC-Formação). Brasília/DF, 2019. Disponível em http://portal.mec.gov.br Acesso em 10 de dezembro de 2020. 
CERTEAU, M. A invenção do cotidiano. Trad. Ephraim Ferreira Alves. 17. ed. Petrópolis, Rio de Janeiro: Vozes, 2011.

FREITAS, A. L. S. de. Pedagogia dos sonhos possíveis: a arte de tornar possível o impossível. In: FREIRE, P. Pedagogia dos sonhos possíveis. São Paulo: Editora UNESP, 2001.

FREIRE, A. M. A. Apresentação a Pedagogia dos sonhos possíveis. In: FREIRE, P. Pedagogia dos sonhos possíveis. São Paulo: Editora UNESP, 2001.

FREIRE, P. Pedagogia da esperança: um reencontro com a Pedagogia do oprimido. 13. ed. Rio de Janeiro: Paz e Terra, 1992.

FREIRE, P. Professora sim, tia não: cartas a quem ousar ensinar. 5. ed. São Paulo: Olho D’Água, 1994.

LINHARES, C. F. S. Sonhar e construir a escola com os professores. In: LINHARES, C. F. S. (org.). Formação continuada de professores: comunidade científica e poética - uma busca de São Luis do Maranhão. Rio de Janeiro: DP\&A, 2004.

MELLO, T. de. Faz escuro mas eu canto: porque a manhã já vai chegar. 15. ed. Rio de Janeiro: Civilização Brasileira, 1996.

PAIVA, J; OLIVEIRA, I. B. de. Organização do trabalho pedagógico na educação de jovens e adultos. Módulo integrado IV. Brasília: SESI, 2001.

RICOEUR, P. A memória, a história, o esquecimento. Trad. Alain Fraçois [et al]. Campinas, São Paulo: Editora da Unicamp, 2007.

UNIVERSIDADE FEDERAL RURAL DO SEMIÁRIDO (UFERSA). Projeto Pedagógico do Curso de Licenciatura em Pedagogia. Angicos/RN: 2016.

ZITKOSKI, J. J. Diálogo/dialogicidade. In: STRECK, D. R; REDIN, E; ZITKOSKI, J. J. (orgs.). Dicionário Paulo Freire. 4. ed. Belo Horizonte: Autêntica, 2018.

Recebido em 19 de dezembro de 2020.

Aprovado em 20 de janeiro de 2021.

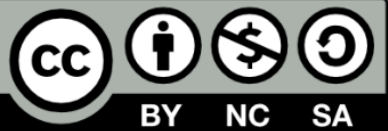

